neuroses, which account for the bulk of psychiatric work, are to an extent the fault of society itself. It follows, therefore, that these three conditions that are close to society should be dealt with not in highly specialized institutions, typified by district general hospitals, but in an environment closer to the homes and workplaces of the patients. In practical terms, this means in the home, where possible, in hostels or in so-called community hospitals, which must include cottage-hospitals, for these are surely still necessary if only in remote country districts.

The medical needs must, therefore, largely if not completely be served by general practitioners supplemented (perhaps supplanted) by skilled nurses, midwives, social workers, and health visitors, all of whom deserve a much greater degree of professional freedom than is at present vouchsafed them. - I am, etc.,

Chadwell Heath Hospital,

I. M. LIBRACH

Romford, Essex

SIR,-The letter from consultant obstetricians up and down the country (19 February, p. 511) pointing out the critical situation that has developed in many departments is an astonishing testimony to the indifference of the Department of Health and Social Security to this problem.

Evidence is now available from many sources of the repeated requests by consultants and their respective boards for an increase in staff at the intermediate level. At a time when the Department has actively encouraged the transfer of domiciliary obstetrics to the hospital (where an almost revolutionary change in intensive care methods in the labour wards has occurred, not to mention the increased work load in the abortion field) the denial by the Department of safe levels of staffing can surely be nothing less than negligent?

In the circumstances underlined in the letter referred to, the obstetrician must surely ask himself how much longer he can continue to accept responsibility, and the Department ask how far it will accept responsibility on his behalf.

It is only by constant supervision and active participation on the part of the consultants in many instrumental deliveries that a possible disaster resulting from the in experience of the junior staff can be avoided. However, it is not always possible for a consultant to be immediately available and ye the presence of a doctor with sufficient clinical experience is surely indispensible in the practice of safe obstetrics.-We are, etc.

EUNICE R. BURTON Brentwood Group of Hospitals,

DAvid M. C. Forster Essex

\section{Vasectomy in General Practice}

SIR,- It is perhaps in the field of vasectomy that the family doctor can make his greatest increased contribution to population control In this practice, vasectomy is freely available-and available free-in the doctor's own surgerv, to National Health Service patients.

In our group practice of five doctors with a list of about 13,000 patients, we perform an average of two vasectomies a week. A preliminary survey of 100 consecutive vasec- tomies completed in 1971 has shown no untoward incidents. All couples concerned were carefully interviewed and this was easy because all the couples are patients of the practice. The operations were performed according to one or other of the recognized techniques described in the literature (31 October, 1970, p. 295)

Complications have been limited to minor local bruising; in no case has it been necessary to call in consultant help, and thus there has been no call on hospital resources. Time required off work has averaged abou two days. Patients have been spared the embarrassment of having had to involve anyone else in the arrangements for vasectomy, and have been able to have it performed on the doctor's own premises, and without having to be on a waiting list for more than a week or so.

It is a very acceptable method of family completion, and the technique is simple, easily learned, and within the competence of any interested family doctor; it does not need to be limited to surgeons or hospitals The demand for vasectomy continues, and it is probably still true to say that "interest in male sterilization in the community is considerable, and the demand for the operation far outstrios the services available" (31 October 1970, p. 295).-I am, etc.,

Ashington,

J. J. Новвs

Northumberland

\section{Second Opinion: Breast Cancer}

SIR,-The surgeon in his letter to the genera practitioner in "Second Opinion, Please" (11 March, p. 681) says that the histological re port on Mrs. C. D.'s breast cancer "gives us little guide as to prognosis," but he does go on to quote an $\mathbf{8 0} \%$ chance of five-year survival.

Although. as implied in the letter, the degree of differentiation of the tumour and especially the presence or absence of lymph node involvement are important, there are other factors such as the site of the tumour, the character of its margins, blood vessel invasion, and lymphocytic infiltration that may influence the prognosis. Size is also factor, and with respect, I prefer a pathologist's measurement in the laboratory to the surgeon's preoperative estimation of "about the size of a small chestnut."

If I find a metastasis in only one of say 30 lymph nodes, this probably does not significantly alter the prognosis of an upper outer quadrant tumour; but if Mrs. C. D.' lesion was $3 \mathrm{~cm}$ diameter, in the inner half of the breast, and was invading blood vessels I would not be so optimistic as her surgeon, despite the absence of axillary involvement.

The pathologist may not be able to dogmatize over individual cases, but his examination can usually give some guide to prognosis, which is one reason for sending specimens to him.-I am, etc., Pathologv Department,

W. K. CowaN Gateshead

SIR.-I was sorry to see from the article "Asthma and a Lump in the Breast" (11 March, p. 681) that the influence still per- sists of the incorrect teaching on which so many generations of students were brought up-namely, that the breast should be examined with the flat of the hand. Years ago I tried to trace the source of the error and, though I have forgotten the details, my recollection is that $I$ decided it had arisen from a misunderstanding of a phrase used by Velpeau in the middle of the last century, which was mistranslated "with the flat of the hand" instead of the correct "with the hand flat." However that may be, the flat of the hand is a crude instrument of palpation compared with the pulps of the fingers.

The correct way to palpate the breast is between the pulps of the fingers and the chest wall, and to do this the hand must be held flat. This is the real importance of "the flat of the hand" in examination of the breast.-I am, etc.,

London W.1

David Patey

\section{Doctors and Overpopulation}

SIR,-Dr. P. Moxon (11 March, p. 693) raises some interesting points. He states that the birth rate of a number of European countries including Federal Germany, Sweden, Denmark, Finland, Portugal, Czechoslovakia, and Hungary has fallen below the replacement rate. Yet reference to the 1971 World Population Data Sheet, issued by the Population Reference Bureau and based on figures supplied by the United Nations, clearly demonstrates that in all of these countries birth rates significantly exceed death rates. Furthermore, the times given for these countries to double their population range from 100 years in the case of Portugal to 175 years for Federal Germany, Finland, and Hungary.

With respect to the British scene all responsible predictions, including that prepared during 1971 by the Government Actuary, indicate a gradual rise in the United Kingdom population in ensuing decades. In 1970 our population stood at 55.8 million; the Actuary's projection for 2000 A.D. is 66.5 million and for 2010 A.D. 70.9 million. The quality of our lives in these islands is being continually eroded by our population growth. In association with governmental policies of economic growthmanship it contributes to environmental pollution of air, water, and land, and it exacerbates the rate at which we deplete our resources of metals, fossil fuels, water, and timber. Overpopulation increases demands for state services such as houses, schools, and roads, and it imposes further strains on our already overtaxed National Health Service.

Global overpopulation is the transcendent problem of the last third of the 20th century. Based on available figures for population density the United Kingdom ranks eighth in the league of overpopulated nations while England and $W$ ales is second only to Taiwan. The danger to future generations mentioned in Dr. Moxon's letter will not arise from attempts to stabilize or reduce the population of Britain or of the world but will be a direct result of continuing population growth.-I am, etc.,

JOHN A. LORAINE,
JOHN A. LORAINE,
Chairman,
Doctors and Overpopulation Group

MRC Clinical Endocrinological Unit,
Edinburgh 